
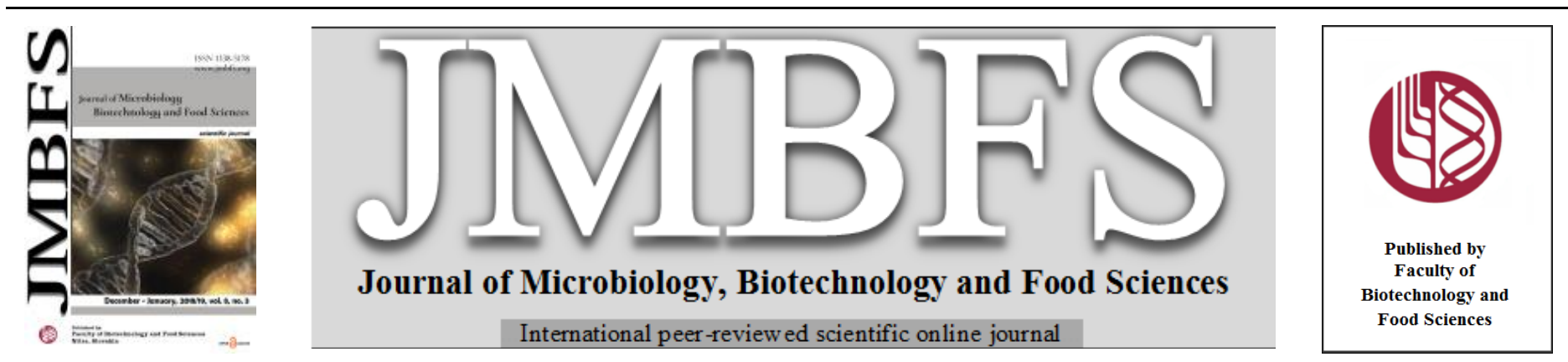

\title{
EFFECT OF PROCESSING PROCEDURES ON IN VITRO DIGESTIBILITY AND COLONIC FERMENTATION OF RICEBERRY RICE
}

\author{
Francis Ayimbila ${ }^{1}$ and Suttipun Keawsompong ${ }^{* 1,2}$
}

Address(es): Suttipun Keawsompong, Ph.D.

${ }^{1}$ Specialized Research Units: Prebiotics and Probiotics for health, Department of Biotechnology, Faculty of Agro-Industry, Kasetsart University, Bangkok 10900, Thailand.

${ }^{2}$ Center for Advanced Studies for Agriculture and Food, KU Institute of Advanced Studies, Kasetsart University )CASAF, NRU-KU(, Bangkok 10900, Thailand. Tel.: +66 0-2562-5074; Fax: +66 0-2579-4096.

*Corresponding author: fagisuk@ku.ac.th

doi: 10.15414/jmbfs.2018-19.8.3.940-946

\section{ARTICLE INFO}

Received 10.3. 2018

Revised 5. 10. 2018

Accepted 9. 10. 2018

Published 1. 12. 2018

\section{Regular article}

OPEN $\partial_{\text {ACCESS }}$

\begin{abstract}
Riceberry is a new rice variety which has recently become popular in Thailand and Asia. Cooling cooked rice influences its digestion; however colonic fermentation studies comparing freshly cooked rice )FCR(, refrigerated rice )RR( and frozen rice )FR( hydrolysates are limited. Here, in vitro digestion rate and colonic fermentation of freshly cooked Thai riceberry rice prepared by conventional rice cooker ) RCM( and boiling method $) \mathrm{BM}$ (, and reheated after 3 days storage $) 4{ }^{\circ} \mathrm{C}$; RR and $-20{ }^{\circ} \mathrm{C}$; FR( were investigated. Starch fractions )\% wet basis( differed between cooking methods due to varied moisture contents. After storage, resistant starch )RS( contents in RR and FR were not significantly different compared to FCR; however, increase in slowly digestible starch )SDS( was accompanied by reduction in rapidly digestible starch (RDS) in riceberry rice cooked by BM. SDS increased from $7.56 \%$ to $16.00 \%$ in refrigerated rice )RR-BM( and by $15.81 \%$ in frozen rice )FR-BM(. Riceberry rice hydrolysates after simulated human upper gut hydrolysis, were not significantly different among treatments and $49.90 \%$ escaped hydrolysis. During in vitro colonic fermentation, riceberry rice hydrolysates significantly enhanced probiotic strains; B. animalis TISTR 2194, B. bifidum TISTR 2129 and L. reuteri KUB AC-5 than pathogens; E. coli E010 and $S$. serovar Enteritidis S003. Colonic fermentation was similar among treatments. Results indicated that cooking riceberry rice by BM and storage reduced starch digestion but colonic fermentation was not dependent on cooking and storage conditions.
\end{abstract}

Keywords: riceberry rice, cooking and storage, digestibility, colonic fermentation

\section{INTRODUCTION}

Composition of gut microbiota impacts on host health through the supply of nutrients which alter metabolism and interact with host cells (Flint, Duncan, Scott and Louis, 2007). Imbalanced human microbiota is associated with inflammatory bowel disease, gastroenteritis, and colon cancer )Venter, 2007(. A proper balance of the microbiota is important and this can be achieved by dietary carbohydrates that escape digestion in the small intestine and enter the colon where they are selectively used by probiotics (Cervantes-Pahm, Liu and Stein, 2014; Marotti et al., 2012). Probiotics are found in the gut microbiota as mostly lactic acid bacteria consisting of multiple strains of the genera Lactobacillus and Bifidobacterium which confer health benefits through their activities. Conversely, pathogenic strains from the genera Escherichia coli and Salmonella are associated with several human diseases. Colonic fermentation of indigestible host diet fraction by probiotic bacteria limits pathogen growth, thereby reducing the risk of colonic cancer and regulating the immune system. Hence, the impact of diet fraction in manipulating gut microflora for host well-being has attracted multiple research interest (Gibson et al., 2004).

Fermentable carbohydrates that escape digestion in the upper gut and selectively stimulate growth and activities of probiotic bacteria in the colon, resulting in host health benefits, are known as prebiotics )Gibson et al., 2017;Gibson and Roberfroid, 1995). Prebiotics serve as food for probiotic bacteria in the colon. Prebiotics are considered important compared to other dietary fibers due to their unique property to be selectively utilized by bifidobacteria or lactobacilli in the colon (Tuohy, Rouzaud, Bruck and Gibson, 2005). Prebiotics are indigestible carbohydrates including resistant starch )RS(, which enhances host health through modulation of probiotic bacteria (Y. K. Lee and Salminen, 2009).

Resistant starch )RS( is defined as total amount of starch and starch degradation products not absorbed in the upper gastrointestinal (GI) tract of healthy humans (Englyst, Kingman and Cummings, 1992). RS is presented to colonic microbiota as a fermentable carbohydrate (Fuentes-Zaragoza et al., 2011). As a result of the relationship between gut microbiota and the host, RS may have the ability to reduce several human diseases (DuPont and DuPont, 2011). RS occurs in rice but the amount depends on processing conditions, especially cooking and low-temperature storage.

Riceberry rice is a purple-pigmented variety cross-bred from Thai Hom Mali rice, Hom Hin rice and Khao Dawk Mali 105 by the Rice Research Center, Kasetsart University, Kamphaeng Saen, Nakhon Pathom, Thailand. This variety is popular in Thailand and its environs due to unique grain characteristics such as fluffy texture, flavor and nutritional value; however, little is known regarding its digestion and colonic fermentation. Rice is eaten freshly cooked or reheated after storage. Cooking methods (Rashmi and Urooj, 2003; Reed, Ai, Leutcher and Jane, 2013) and storage temperatures (Frei, Siddhuraju and Becker, 2003; Sonia, Witjaksono and Ridwan, 2015) both affect rice digestion. Cooking renders the starch rapidly digestible by digestive enzymes due to the gelatinization process and storage gradually converts RDS to SDS and RS through the retrogradation mechanism )Frei et al., 2003; Sonia et al., 2015(. Thai jasmine rice; Hom Mali rice digestion was affected by cooking and storage conditions; SDS increased significantly but RS did not increase after storage )Ayimbila and Keawsompong, 2018(.

Digestibility of rice varies with cooking and storage conditions; however, information regarding in vitro digestion and fermentation of riceberry rice is limited regarding the combined effects of cooking methods and storage temperatures. Here, digestion rates of freshly cooked and reheated stored riceberry rice were compared and the impacts of their hydrolysates on colonic bacteria fermentation were assessed. 


\section{MATERIALS AND METHODS}

\section{Materials}

From a local shop in Bangkok, Thai riceberry rice was purchased, sealed in polyethylene bags and stored at $4{ }^{\circ} \mathrm{C}$ prior to analysis. All chemicals sourced from Sigma-Aldrich (USA( were of analytical grade.

\section{Sample preparation}

Freshly cooked rice )FCR( as control was obtained using the boiling method )BM(/Pilaf or oriental method on a gas cooker with rice to water ratio 1:2, and rice cooker method )RCM( by electric rice cooker )Otto, Kingglass Co., Ltd., Thailand( based on rice to water ratio 1:1.5. Refrigerated rice )RR( and frozen rice )FR( samples were obtained by storing $100 \mathrm{~g}$ of control sample at $4{ }^{\circ} \mathrm{C}$ and $20^{\circ} \mathrm{C}$ for 3 days, respectively. Prior to analysis, stored rice was reheated for $30 \mathrm{~s}$ at $100 \%$ power using a microwave )LG Electronics Co., Ltd., Thailand(. Six treatments were prepared in triplicates from a bag of rice. Apparent amylose content in the raw rice was analyzed by the iodine colorimetric method )Juliano et al., 1981( before cooking.

\section{Quantification of starch fractions}

Approximately $0.5 \mathrm{~g}$ of minced rice was analyzed )Englyst $\boldsymbol{e t}$ al., 1992( with slight modifications. The sample was combined with sodium acetate buffer $) 0.5$ $\mathrm{M}, \mathrm{pH}$ 5.2( containing an enzyme mixture of $10 \mathrm{mg}$ pancreatic $\alpha$-amylase ) $\mathrm{P}$ 7545; Sigma-Aldrich( and $10 \mu \mathrm{L}$ of amyloglucosidase )AMGDF, Megazyme( per $\mathrm{mL}$ with glass beads and incubated horizontally in a shaking water bath for $2 \mathrm{~h}$ at $37^{\circ} \mathrm{C}$. Aliquots of $250 \mu \mathrm{L}$ were taken at 20 and $120 \mathrm{~min}$ and each was placed in a $4 \mathrm{~mL}$ vial of $95 \%$ ethanol. Glucose content was measured using the glucose oxidase-peroxidase method )K-GLUC, Megazyme(. Resistant starch was obtained as the starch remaining undigested after $120 \mathrm{~min}$ of incubation. Starch was classified as rapidly digestible starch )RDS(, slowly digestible starch )SDS(, and resistant starch )RS( per $100 \mathrm{~g}$ on wet basis.

\section{Rice hydrolysis in simulated gastrointestinal )GI( conditions}

In the buccal cavity or mouth condition, approximately $20 \mathrm{~g}$ minced rice was combined with $160 \mathrm{~mL}$ of artificial saliva ) $\mathrm{HCl}$ buffer, $\mathrm{pH}$ of 6.8 ( comprising ) $/ \mathrm{L}\left(; \mathrm{NaCl}, 1.60 ; \mathrm{NH}_{4} \mathrm{NO}, 0.33 ; \mathrm{NH}_{2} \mathrm{PO}_{4}, 0.64 ; \mathrm{KCl}, 0.20 ; \mathrm{K}_{2} \mathrm{C}_{6} \mathrm{H}_{5} \mathrm{O} .7 \mathrm{H}_{2} \mathrm{O}\right.$ $0.31 ; \mathrm{C}_{5} \mathrm{H}_{3} \mathrm{~N}_{4} \mathrm{O}_{3} \mathrm{Na}, 0.02 ; \mathrm{H}_{2} \mathrm{NCONH}_{2}, 1.98$ and $\mathrm{C}_{3} \mathrm{H}_{5} \mathrm{O}_{3} \mathrm{Na}, 0.15$. Human salivary amylase was added to obtain a final concentration of 0.33 units per $\mathrm{mL}$ and incubated for $30 \mathrm{~min}$ at $37^{\circ} \mathrm{C}$

Immediately after mouth hydrolysis, $\mathrm{pH}$ of the medium was adjusted to 2.0 for gastric condition. Pepsin was added to obtain final concentration of 20 units per $\mathrm{mL}$ and incubated for $4 \mathrm{~h}$ at $37^{\circ} \mathrm{C}$.

After gastric condition, the $\mathrm{pH}$ was adjusted to 6.9 following addition of freshly prepared enzyme of porcine pancreatic $\alpha$-amylase solution to obtain a final concentration of $0.75 \mathrm{unit} / \mathrm{mL}$ and incubated at $37{ }^{\circ} \mathrm{C}$ for $6 \mathrm{~h}$ for intestinal condition. Analyses were performed in duplicate. Total starch and reducing sugar content were determined using phenol sulfuric acid and DNS methods, respectively. Hydrolyzed riceberry rice percentage was estimated by the ratio of reducing sugar released to total sugar content using the equation below (Hongpattarakere et al., 2012).

$$
\text { Hydrolysis }(\%)=\frac{\text { Reducing sugar released }(\text { final }- \text { initial sugar })}{\text { Total sugar content }- \text { initial reducing sugar }} \times 100
$$

The remaining hydrolysate was transferred into a dialysis tube $3500 \mathrm{MWCO}$ Cellu Sep Dialysis Membrane 5030-46, Seguin, TX, USA(, and dialyzed against water at $4{ }^{\circ} \mathrm{C}$. After dialysis, glucose content was measured by the glucose oxidase-peroxidase method )K-GLUC, Megazyme( to confirm removal of al glucose and the retentate was freeze-dried )Scan Vac, CoolSafe 110 Vassingerød, Denmark(.

\section{Scanning electron microscope )SEM(}

Morphological characteristics of freeze-dried rice grains of FCR, RR and FR for both cooking methods, and minced FCR by RCM before and after digestion with human salivary $\alpha$-amylase, pepsin and pancreatic $\alpha$-amylase were observed using high resolution )HR( SEM (Quanta 200 FEG, FEI, Eindhoven, The Netherlands) Grains were fractured using a razor blade. Samples were placed on double adhesive tape fixed on a metallic stub, coated with gold and viewed at appropriate resolutions.

\section{In vitro fermentation}

Bacterial-riceberry rice hydrolysate fermentations were tested in duplicate Overnight cultured inocula (1\%) of five bacteria strains (Table 1), adjusted to $0.5-0.6 \mathrm{OD}$ at $600 \mathrm{~nm}$ were cultivated in sterilized $5 \mathrm{~mL}$ appropriate basal broth with or without $1 \%$ hydrolysates (control). Lactobacillus was cultivated in MRS broth at $37{ }^{\circ} \mathrm{C}$ aerobically at $4 \mathrm{~h}$ intervals to $16 \mathrm{~h}$. Bifidobacterium species were cultivated in MRS- $0.005 \mathrm{~L}$-cysteine $\mathrm{HCl}$ broth at $37^{\circ} \mathrm{C}$ at $6 \mathrm{~h}$ intervals to $24 \mathrm{~h}$, anaerobically (Bactron IV, Anaerobic Chamber, Shel Lab, Cornelius, OR, USA) Escherichia coli KUB-E010 and Salmonella serovar Enteritidis KUB-S003 were cultivated in nutrient broth $(\mathrm{NB})$ at $37^{\circ} \mathrm{C}$ at $4 \mathrm{~h}$ intervals to $16 \mathrm{~h}$. Samples were taken and appropriate dilution factors were spread plated and incubated overnight. Colony forming units $(\mathrm{CFU} / \mathrm{mL}$ ) at various time points (h of incubation) were counted within 25 to 250 and data were recorded (Phothichitto, Nitisinprasert and Keawsompong, 2006; Vulevic, Rastall and Gibson, 2004).

$\log \mathrm{CFU} / \mathrm{mL}$ of each strain was determined and specific growth rate $) \mu, \mathrm{h}^{-1}($ obtained by the equation below:

$\mu\left(\mathrm{h}^{-1}\right)=\left(\ln N_{t}-\ln N_{0}\right) /(\mathrm{t})$,

where $N$ is the $\log \mathrm{CFU} / \mathrm{mL}$ of bacteria after time interval $\mathrm{t}$ in $\mathrm{h}, N_{0}$ is the initial number of bacteria, and $\mu$ is the specific growth rate in $\mathrm{h}^{-1}$.

Table 1 Bacterial strains tested and their cultivated conditions

\begin{tabular}{|c|c|c|}
\hline Bacterial strain & Medium & Growth condition \\
\hline Lactobacillus reuteri KUB-AC5 & MRS (Difco, USA) & Incubated; $37^{\circ} \mathrm{C}, 16 \mathrm{~h}$ \\
\hline Bifidobacterium bifidum TISTR 2129 & MRS+005 L-cysteine (Difco, USA) & Incubated; $37^{\circ} \mathrm{C}, 24 \mathrm{~h}$, anaerobically \\
\hline Bifidobacterium animalis TISTR 2194 & MRS+005 L-cysteine (Difco, USA) & Incubated; $37^{\circ} \mathrm{C}, 24 \mathrm{~h}$, anaerobically \\
\hline Escherichia coli $\mathrm{E} 010$ & Nutrient broth (Merck, Germany) & Incubated; $37^{\circ} \mathrm{C}, 16 \mathrm{~h}$, shaking \\
\hline Salmonella serovar Enteritidis S003 & Nutrient broth (Merck, Germany) & Incubated; $37^{\circ} \mathrm{C}, 16 \mathrm{~h}$, shaking \\
\hline
\end{tabular}

\section{Data analysis}

Replicate data were analyzed by one-way analysis of variance (ANOVA) with cooking methods and storage temperatures as factors using statistical analysis of SPSS version 19. Significant differences in rates of digestion between means of treatments were determined. Degrees of significances were set at $p=0.05$ for all experiments.

Six riceberry rice hydrolysates and a basal medium without carbon source as control were evaluated. The criterion for data analysis was defined as follows; if specific growth rate of the bacterial strain with hydrolysate was statistically lower or equal to growth of the control, then the hydrolysate did not enhance growth of that strain; however, if specific growth rate was statistically higher than the control, then the hydrolysate enhanced bacterial growth.

\section{RESULTS AND DISCUSSION}

Effect of cooking and storage conditions on starch fractions

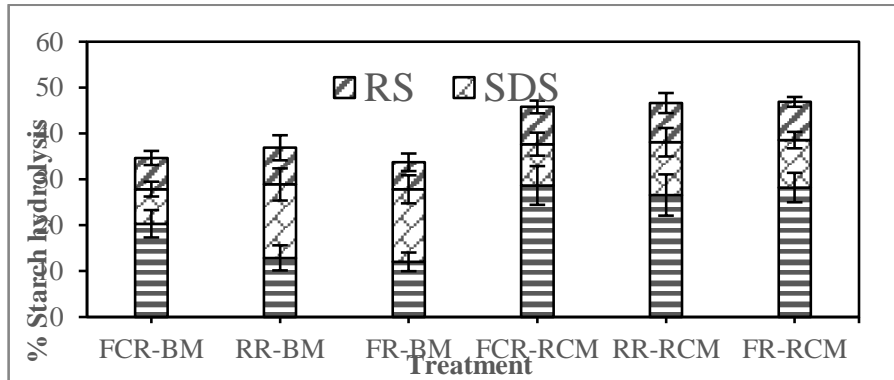

Figure 1 Starch fractions ) g/100 g, eaten basis( of cooked riceberry rice by boiling method $) \mathrm{BM}($ and rice cooker method $) \mathrm{RCM}$ (. Freshly cooked rice )FCR(, refrigerated rice )RR(, frozen rice )FR(. Values are mean \pm standard deviation of rapidly digestible starch )RDS(, slowly digestible starch )SDS( and resistant starch )RS( of three replicates. Error bars show standard deviation, $p>0.05$. 
Starch fractions of freshly cooked rice )FCR(, reheated refrigerated rice )RR( and frozen rice )FR( of riceberry rice prepared by boiling method )BM( and rice cooker method )RCM( are displayed in Figure 1. Mean percentage of amylose before cooking was $13.68 \pm 0.58$. Mean percentage moisture content of riceberry rice cooked by boiling method was $55.33 \pm 0.88$ and riceberry rice cooked by rice cooker method was $44.83 \pm 0.78$. For the boiling method, FCR-BM recorded $20.32 \%$ rapidly digestible starch )RDS(, 7.56\% slowly digestible starch )SDS( and $6.78 \%$ resistant starch )RS(, while FCR-RCM produced $28.67 \%$ RDS, $9.0 \%$ SDS and $8.11 \%$ RS. Between cooking methods, total starch )TS( content varied significantly, hence starch fractions were significantly different. This was attributed to significant variation of moisture content $)>10 \%$ (. Cooking caused starch gelatinization of riceberry rice as water intake replaced hydrogen bonds between the starch molecules. Increased amounts of water used in BM resulted in well-cooked rice, and high temperature caused greater intake of water which reduced TS content.

Boiling method $) B M($

FCR-BM
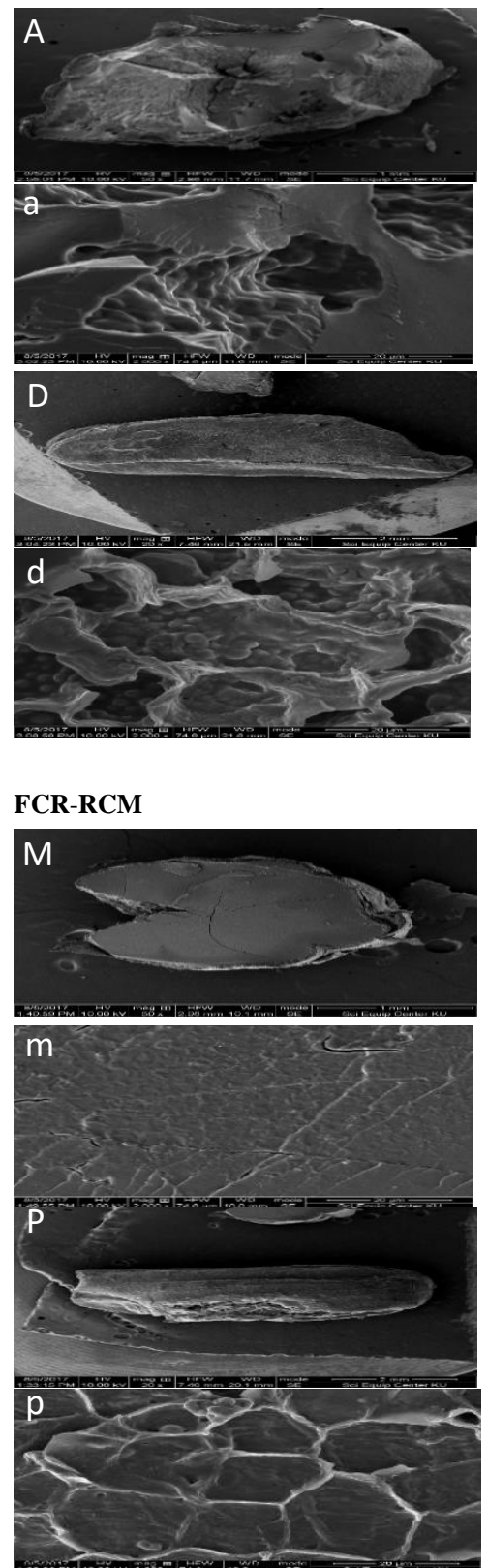

RR-BM
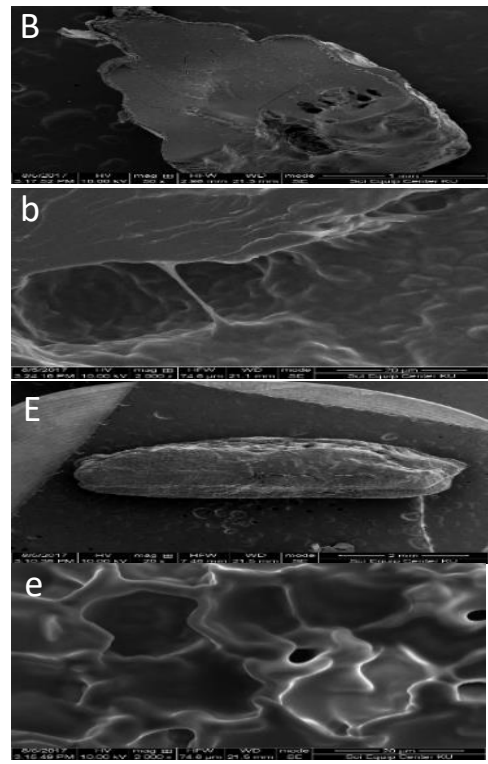

Rice cooker method )RCM(

RR-RCM
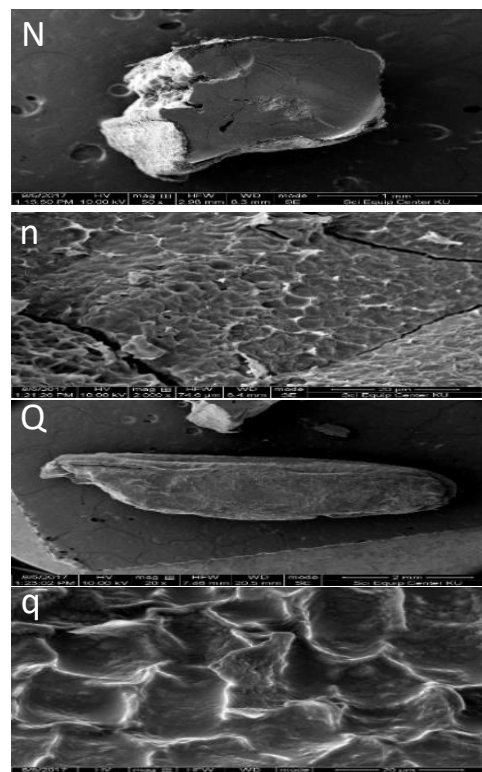

FR-BM
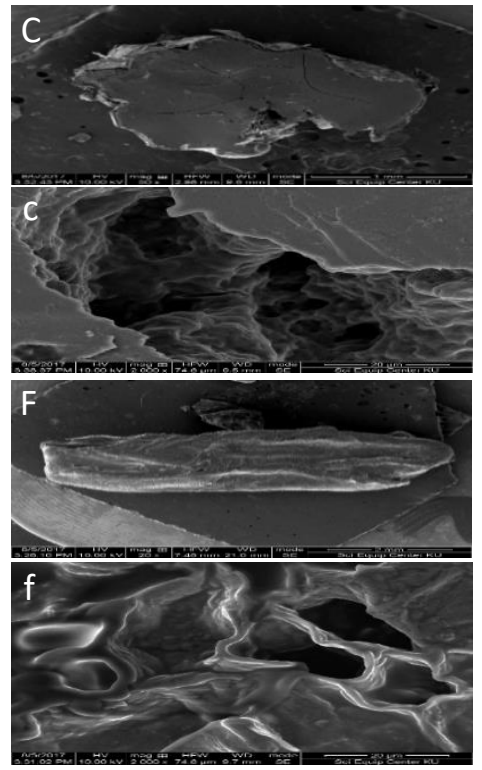

FR-RCM
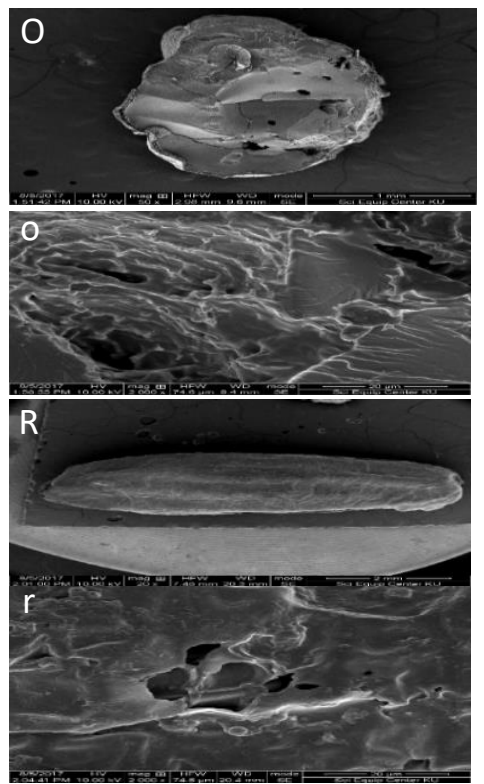

Figure 2 Scanning electron micrographs of cross-sectional and longitudinal surfaces of cooked riceberry rice grains by boiling method; FCR-BM, RR-BM and FR-BM and rice cooker method; FCR-RCM, RR-RCM and FR-RCM. Cross sections )boiling method; A-C, rice cooker method; M-O( and longitudinal surface )boiling method; D-F, rice cooker method; P-R(. Freshly cooked rice )FCR(, refrigerated rice )RR(, and frozen rice )FR(. Lowercase letters show higher magnification of samples labeled with uppercase.

Refrigeration and freezing decreased RDS content and significantly increased SDS content in both cooking methods compared to FCR but RS ) $<10 \%$ ( was not significantly $)>0.05$ ( different (Figure 1). Compared to FCR-BM, RR-BM gave a lower RDS content of $12.89 \%$, higher SDS of $16.0 \%$ and RS of $7.99 \%$. Likewise, FR-BM gave lower RDS of $12.02 \%$, higher SDS of $15.81 \%$ and RS of $5.89 \%$. Compared to FCR-RCM, RR-RCM gave a lower RDS content of $26.59 \%$, higher SDS of $11.50 \%$ and similar RS of $8.54 \%$. FR-RCM recorded similar RDS of $28.59 \%$, SDS of $10.34 \%$ and RS of $8.33 \%$. Storage affected riceberry rice digestion as the retrogradation mechanism caused reorganization of gelatinized starch molecules. Starch retrogradation caused an imperfect crystalline structure through interaction between long-chain and highly-branched amylopectin )Park, Baik and Lim, 2009; Zhang, Hu, Xu, Jin and Tian, 2011(. This increased SDS in riceberry rice depends on cooking methods but with no significant difference between storage temperatures. Differences were attributed to varied amounts of water which play a crucial role in starch gelatinization and retrogradation mechanisms during cooking and storage of starchy foods. The rate of starch retrogradation was highly influenced by the amount of water absorbed (Wang and Copeland, 2013). 
Impact of cooking methods and storage on starch fractions as evidenced by SEM micromorphology

From Figure 2, FCR-BM rice )images $\mathrm{A}$ and $\mathrm{D}$ ( showed more and larger cracks on the cross-sectional surface; image A and longitudinal surface; image D than FCR-RCM )images $M$ and $P($ rice cross-sectional surface; image $M$ and longitudinal surface; image $\mathrm{S}$ indicating the effect of water quantity used during cooking. Cracks in grains provided a medium for water penetration into the grains during cooking. Using lower amounts of water resulted in dense regions with less starch gelatinization in FCR-RCM riceberry rice, while higher amount of water in BM caused dense voids in FCR-BM. This confirmed the differences in starch fractions between cooking methods.

RR-BM riceberry rice; images $\mathrm{B}$ and $\mathrm{E}, \mathrm{FR}-\mathrm{BM}$ riceberry rice; images $\mathrm{C}$ and $\mathrm{F}$, $\mathrm{RR}-\mathrm{RCM}$ riceberry rice; images $\mathrm{N}$ and $\mathrm{Q}$ and $\mathrm{FR}-\mathrm{RCM}$ riceberry rice; images $\mathrm{O}$ and $\mathrm{R}$ gave more and larger voids than their respective FCR grains. During storage, water relocation inside the gelatinized rice starch occurs as hydrogen bonds between water and starch molecules dissociate through a process of retrogradation. The disruption of hydrogen bonds between water and starch is the first step for retrogradation (H. Lee, Lee and Kim, 2017; Ogawa, Glenn, Orts, and Wood, 2003).The re-association of the starch molecules after 3 days storage increased cracks in riceberry rice grains, which influenced by cooking conditions.

In vitro rate of hydrolysis in simulated gastrointestinal (GI) conditions

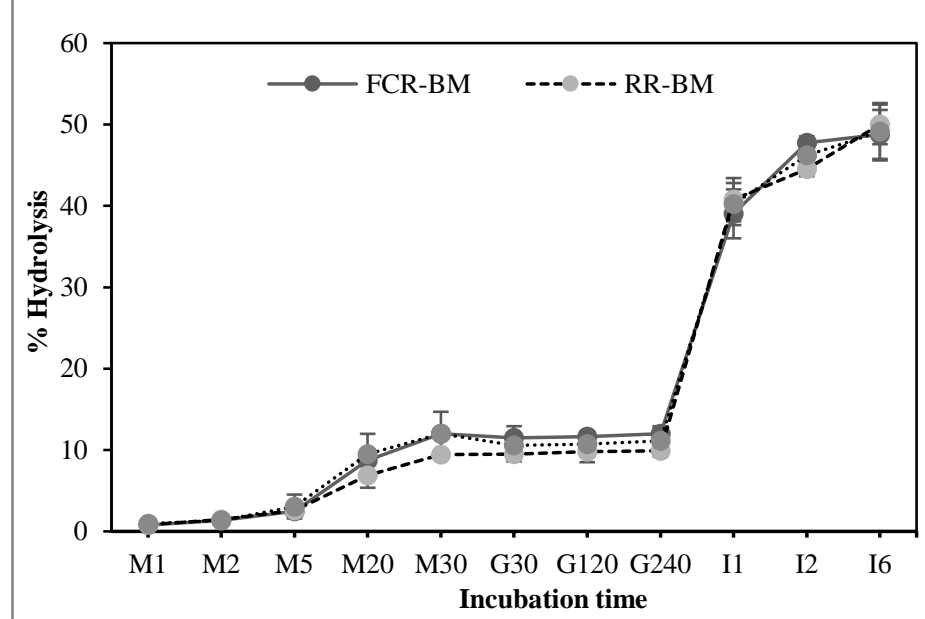

Figure 3 Rate of hydrolysis (\%) of riceberry rice prepared by boiling method (BM) in simulated gastrointestinal (GI) conditions.

Freshly cooked rice; FCR-BM, refrigerated rice; RR-BM, frozen rice; FR-BM Human salivary $\alpha$-amylase in the mouth condition )M1; 1 min, M2; 2 min, M5; 5 min, M20; 20 min, M30; 30 min(; pH 6.8, pepsin in human gastric juice )G30; 30 $\min , \mathrm{G} 120 ; 120 \mathrm{~min}, \mathrm{G} 240 ; 240 \mathrm{~min}(; \mathrm{pH} 2.0$ and porcine pancreatic $\alpha$-amylase in the intestinal condition $) \mathrm{I} 1 ; 1 \mathrm{~h}, \mathrm{I} 2 ; 2 \mathrm{~h}, \mathrm{I} 6 ; 6 \mathrm{~h}(; \mathrm{pH} 6.9$. Error bars show standard deviation, $p>0.05$

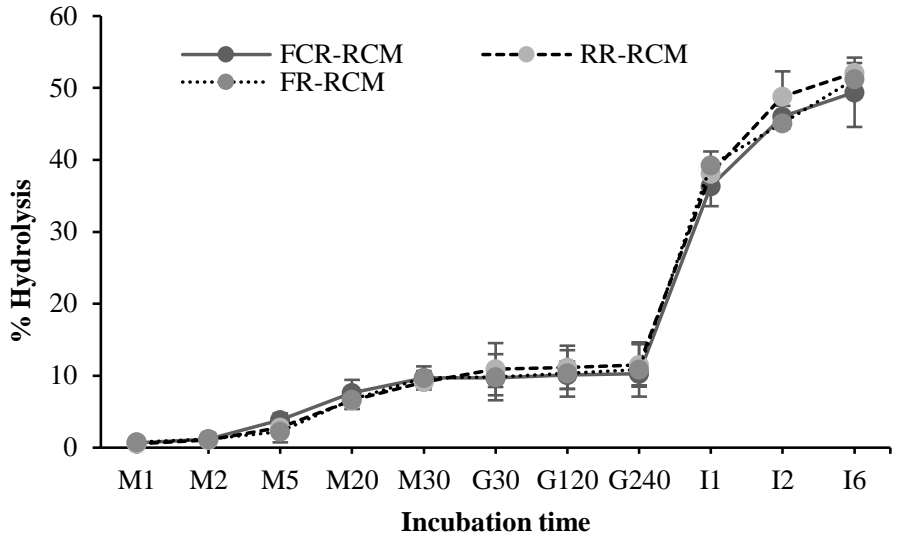

Figure 4 Rate of hydrolysis )\%( of riceberry rice prepared by rice cooker method )RCM( in simulated gastrointestinal )GI( condition. Freshly cooked rice; FCRRCM, refrigerated rice; RR-RCM, frozen rice; FR-RCM. Human salivary $\alpha$ amylase in the mouth condition )M1; $1 \mathrm{~min}, \mathrm{M} 2 ; 2 \mathrm{~min}$, M5; $5 \mathrm{~min}, \mathrm{M} 20 ; 20$ min, M30; $30 \mathrm{~min}(; \mathrm{pH} 6.8$, pepsin in human gastric juice )G30; $30 \mathrm{~min}$ G120;120 min, G240; $240 \mathrm{~min}(; \mathrm{pH} 2.0$ and porcine pancreatic $\alpha$-amylase in the intestinal condition )I1; 1 h, I2; 2 h, I6; 6 h(; pH 6.9. Error bars show standard deviation, $p>0.05$

\section{Hydrolysis rate of riceberry rice in simulated buccal cavity condition}

The human buccal cavity or mouth was mimicked to provide the first condition for digestion using artificial saliva; riceberry rice was partially hydrolyzed Recorded hydrolysis rate of riceberry rice increased with incubation time as shown in Figures 3 and 4 above. Hydrolysis rates (Figure 3) of freshly cooked riceberry rice (FCR-BM) at 1, 2, 5, 20 and $30 \mathrm{~min}$ were $0.72,1.35,2.47,8.71$ and 10.98 , respectively, while refrigerated riceberry rice (RR-BM) gave $0.82,1.45$, $2.58,6.88$ and 9.45 , respectively. In the same trend, frozen riceberry rice (FR$\mathrm{BM})$ gave $0.95,1.35,3.06,9.48$ and 11.99, respectively. Also, hydrolysis rates (Figure 4) of freshly cooked riceberry rice (FCR-RCM) was 0.66, 1.20, 3.85, 7.61 and 9.70, respectively. Likewise, percentage hydrolysis of refrigerated riceberry rice (RR-RCM) were $0.53,1.09,2.83,6.55$ and 9.14 , respectively, while that of frozen riceberry rice (FR-RCM) were $0.77,1.19,2.25,6.71$ and 9.68 , respectively. These results suggested that hydrolysis rates of freshly cooked, reheated, refrigerated and frozen riceberry rice in the buccal cavity were similar and reached a maximum of 9.14-10.98\%. Hydrolysis was not significantly influenced by cooking methods and storage. Riceberry rice prepared by $\mathrm{BM}$ and RCM showed $89.19 \%$ and $90.49 \%$ resistance in simulated human buccal cavity conditions. Salivary $\alpha$-amylase acted partially on riceberry rice. A similar effect on Thai jasmine rice was reported by Ayimbila and Keawsompong (2018).

\begin{tabular}{|c|c|c|c|c|c|c|}
\hline & FCR-RCM & RR-RCM & FR-RCM & FCR-BM & RR-BM & FR-BM \\
\hline$\%$ Resistance & $49.79 \pm 0.72$ & $51.40 \pm 0.72$ & $50.62 \pm 0.57$ & $52.41 \pm 1.16$ & $51.97 \pm 0.64$ & $50.56 \pm 1.18$ \\
\hline
\end{tabular}

Data are mean from three replicates \pm standard deviations, $p>0.05$.

\section{Hydrolysis rate of riceberry rice in artificial human gastric juice}

Riceberry rice hydrolysis in gastric juice containing pepsin was studied Hydrolysis rates of freshly cooked riceberry rice )FCR-BM( at 30, 120 and 240 min were $11.51,11.63$ and 11.99 , respectively, while those of refrigerated riceberry rice )RR-BM( were 9.49, 9.82 and 9.98, respectively. Similarly, hydrolysis rates of frozen riceberry rice )FR-BM( were $10.57,10.74$ and 11.11 , respectively. Riceberry rice cooked by $\mathrm{BM}$ gave $89.00 \%$ resistance in gastric juice. Likewise, hydrolysis rates of freshly cooked riceberry rice )FCR-RCM( were $9.72,10.08$ and 10.26, respectively, while those of refrigerated riceberry rice )RR-RCM( were $10.91,11.17$ and 11.52 , respectively. Similarly, frozen riceberry rice )FR-RB( recorded 9.79, 10.32 and 10.87, respectively. A total of $89.11 \%$ of RCM rice was resistant. Hydrolysis rates of FCR, RR and FR for both cooking methods were also similar and reached a maximum of 9.98-11.99 at 240 minutes. Riceberry rice was resistant to hydrolysis in the gastric condition because starch is the main component; however, some hydrolysis occurred due to the acid effect (Singh, Kaur and Singh, 2013).

\section{Hydrolysis rate of Riceberry rice in intestinal condition}

Riceberry rice was rapidly hydrolyzed under simulated small intestine condition (I) after $1 \mathrm{~h}$ of incubation as shown in Figure 3. Hydrolysis rates of freshly cooked riceberry rice (FCR-BM) at 1, 2 and $6 \mathrm{~h}$ were 39.02, 47.77 and 48.78, respectively, while those of refrigerated riceberry rice (RR-BM) were 40.76 , 44.54 and 50.01, respectively. Likewise, hydrolysis rates of frozen riceberry rice (FR-BM) were 40.22, 46.21 and 49.11, respectively. Hydrolysis rates of freshly cooked riceberry rice (FCR-RCM) were 36.35, 46.00 and 49.46, respectively. Hydrolysis rates of refrigerated riceberry rice (RR-RCM) were 38.11, 48.78 and 52.10 , respectively. Similarly, hydrolysis rates of frozen riceberry rice (FRRCM) were 39.26, 45.12 and 51.22, respectively. Hydrolysis rates of FCR, RR and FR by both cooking methods showed similar trends. Percentage resistance was determined (Table 2) based on the amounts not converted to reducing sugars A total of $49.90 \%$ of riceberry rice was resistant to hydrolysis. Final starch hydrolysates by $\alpha$-amylase were mainly maltose, maltotriose, and maltotetraose from the amylose portion of starch (Yook and Robyt, 2002) and dextrins or branched oligosaccharides from the amylopectin component (Kuriki and Imanaka, 1999). This result indicated that $\alpha$-amylase did not entirely convert riceberry rice to reducing sugars but resulted in $49.90 \%$ oligosaccharides as nonreducing sugars. In simulated GI conditions, $50.07 \%$ of jasmine rice hydrolysate 
escaped hydrolysis in simulated gastrointestinal tract (Ayimbila and Keawsompong, 2018). In this study, mean percentage amylose content of riceberry rice was $13.68 \pm 0.58$. Ayimbila and Keawsompong (2018) reported the mean percentage amylose of jasmice rice (Thai Hom Mali rice) to be $15.54 \pm 1.02$. Both rice varieties are comparable in terms of amylose and are also genetically related; riceberry rice was cross-bred from three rice varieties including Thai
Hom Mali rice, thus, this have resulted in similar percentage resistant to hydrolysis in the simulated GI tract.

SEM micromorphology of riceberry rice hydrolysates showing hydrolysis in the human simulated condition
$\mathbf{A}$

$100 \times$

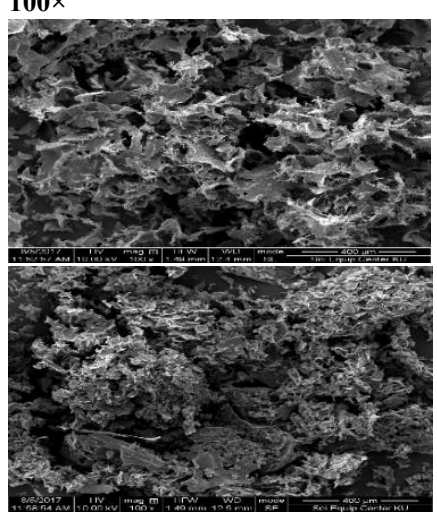

G

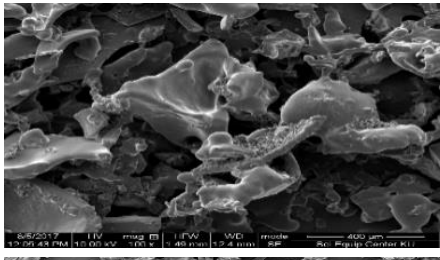

I

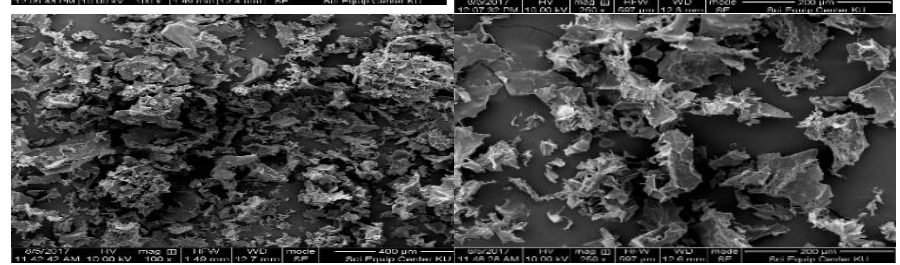

$250 \times$
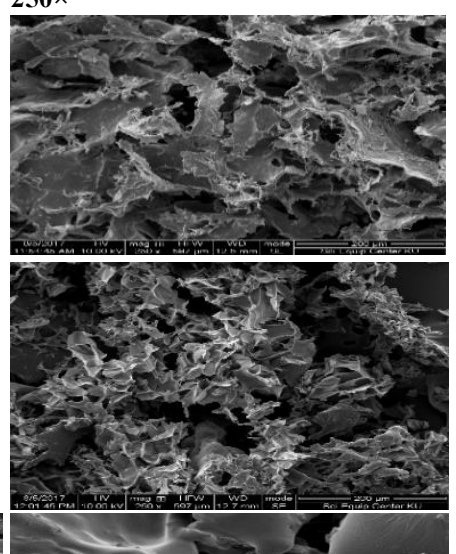

$500 \times$
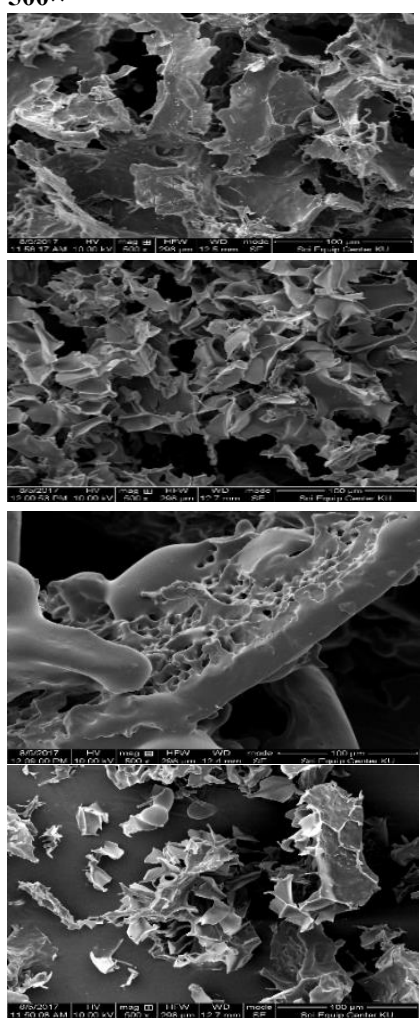

Figure 5 Scanning electron microscope images )different magnifications( of minced cooked riceberry rice before )A( and after hydrolysis during simulation of human buccal cavity or mouth $) \mathrm{M}($, gastric $) \mathrm{G}$ ( and small intestine )I( conditions.

Figure 5 shows that the structure of minced cooked riceberry rice (FCR) before hydrolysis (B) had large connective structures. After digestion by artificial human saliva (M), these structures disconnected into smaller units as a result of salivary amylase activities. Subsequently, further breakdown of structures was observed with voids on the surface of starch compounds after gastric condition $(\mathrm{G})$, possibly due to the acid effect on the bran layer. Finally, much smaller units were observed in the small intestine condition, indicating maximum hydrolysis effect of pancreatic $\alpha$-amylase on riceberry rice. Finally, most compound granules retained their shapes and structures and were resistant to hydrolysis in the simulated human upper gut. These results confirmed that salivary amylase, gastric condition and pancreatic $\alpha$-amylase manage to digest riceberry rice although most hydrolysis was carried out by pancreatic $\alpha$-amylase.

\section{Bacteria fermentation}

Changes in bacteria population

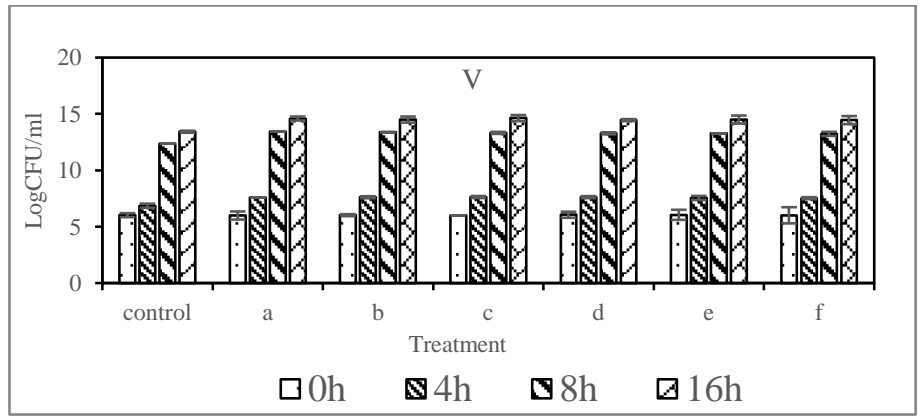

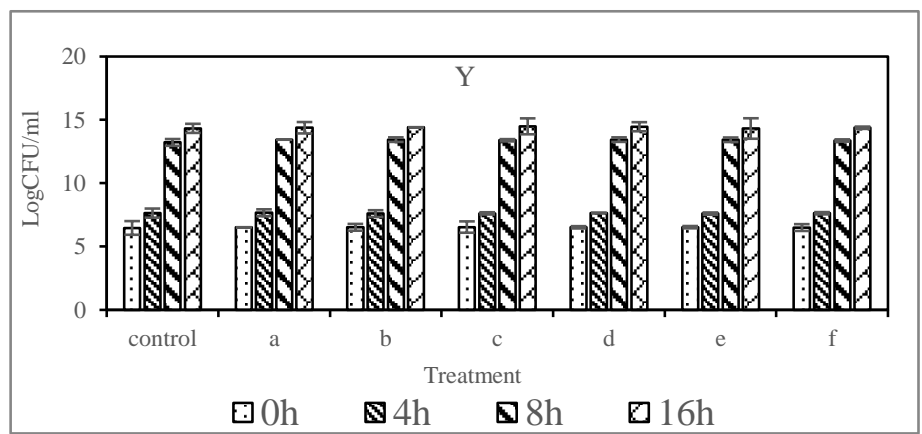

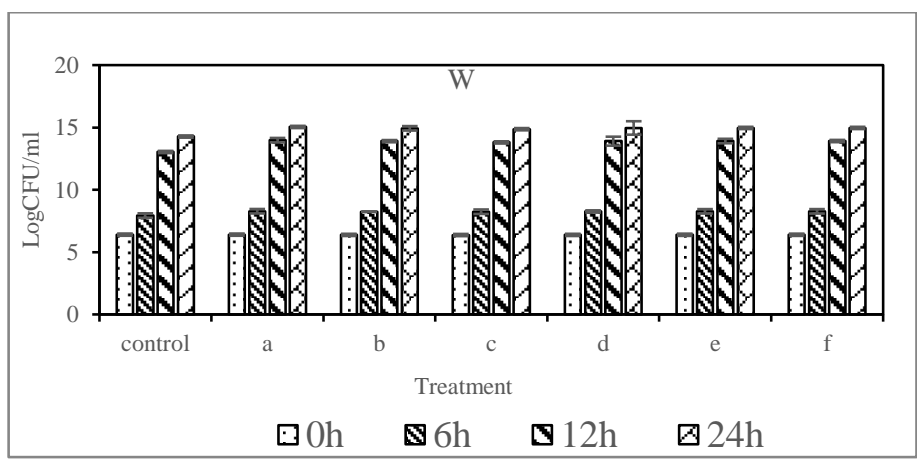



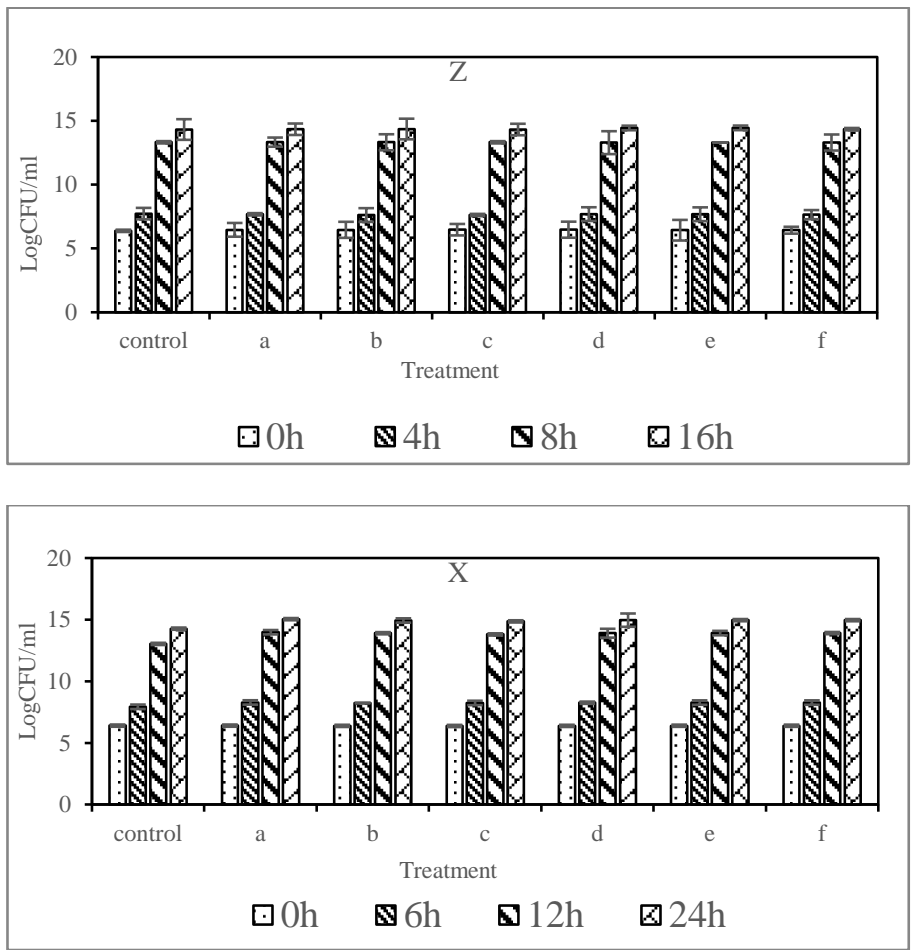

Figure 6 Mean population $(\log \mathrm{CFU} / \mathrm{mL})$ of bacteria in medium with or without (control) riceberry rice hydrolysates over time (h) of fermentation. Rice cooker method (RCM); FCR-RCM (a), RR-RCM (b), FRR-RCM (c), and boiling method (BM); FCR-BM (d), RR-BM (e), FR-BM (f). Values are mean \pm standard deviation. Error bars show standard deviations, $P<0.05$. Lactobacillus reuteri KUB AC-5 (V), Bifidobacterium animalis TISTR 2194 (W), Bifidobacterium bifidum TISTR 2129 (X), Escherichia coli E010 (Y) and Salmonella serovar Enteritidis S003 (Z).

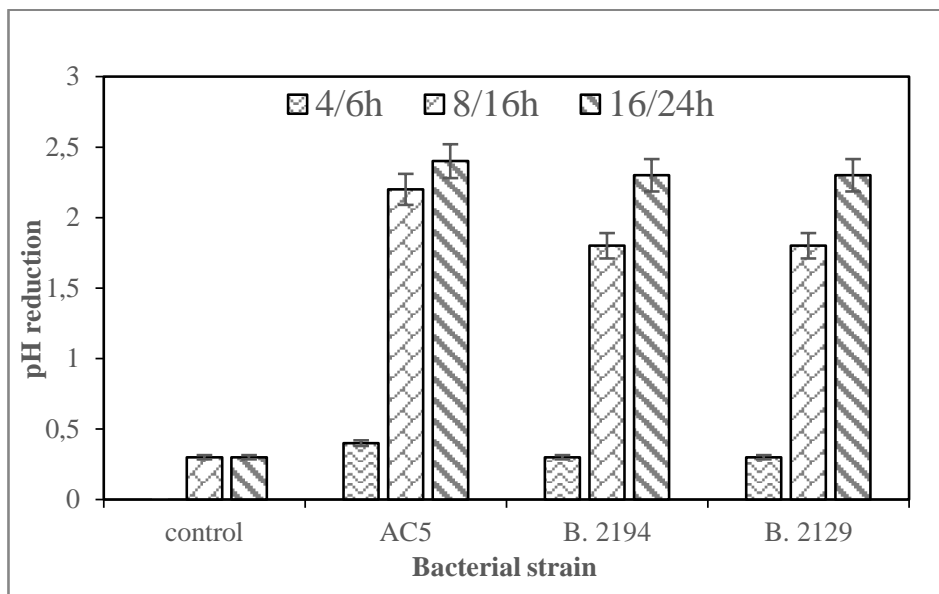

Figure $7 \mathrm{pH}$ reduction in medium with or without (control) riceberry rice hydrolysate over time of fermentation by Lactobacillus reuteri AC5 (AC5); 4h, 8h and 16h, Bifidobacterium animalis TISTR 2194 (B.2194) and Bifidobacterium bifidum TISTR 2129 (B.2129); 6h, 12h and 24h. Initial pH was $6.8 \pm 0.1$

The population ) $\log \mathrm{CFU} / \mathrm{mL}$ ( of probiotic and pathogenic bacterial strains during fermentation of riceberry rice hydrolysates over time is shown in Figure 6 above. All strains exhibited similar changes in population among treatments, which were strain-dependent. Based on the respective control of probiotics, range of growth changes ) $\log \mathrm{CFU} / \mathrm{mL}$ (among treatments after $4 \mathrm{~h}, 8 \mathrm{~h}$ and $16 \mathrm{~h}$ for $L$. reuteri KUB-AC5 were 0.76-0.79, 1.02-1.06 and 1.01-1.05, respectively. Moreover, growth changes ) $\log \mathrm{CFU} / \mathrm{mL}$ ( after $6 \mathrm{~h}, 12 \mathrm{~h}$ and $24 \mathrm{~h}$ for $B$. animalis TISTR 2194 were $0.32-0.35,0.86-0.89$ and $0.64-0.69$, while those of $B$. bifidum TISTR 2129 were $0.62-0.67,0.92-0.94$ and 1.32 , respectively. On the other hand, growth changes ) $\log \mathrm{CFU} / \mathrm{mL}$ ( of pathogenic strains among treatments after $4 \mathrm{~h}$, $8 \mathrm{~h}$ and $16 \mathrm{~h}$ for E. coli E010 were -0.01-0.02, 0.17-0.2 and 0.01-0.02, while those of $S$. serovar Enteritidis S003 were -0.05-0.02, 0 and 0.0-0.04, respectively. Significantly ) $p>0.05$ ( changes of Bifidobacterium animalis TISTR 2194 Lactobacillus reuteri KUB-AC-5 and Bifidobacterium bifidum TISTR 2129 were observed over time compared to control of basal medium. Likewise, population of Escherichia coli E010 and Salmonella serovar Enteritidis S003 changed over time but were not significantly ) $p<0.05$ ( different from control. Thus, riceberry rice hydrolysates enhanced the growth of probiotic bacteria, while pathogens were neither enhanced nor inhibited by riceberry hydrolysates. Also, hydrolysates FCR, RR and FR of riceberry rice gave similar fermentation for each strain Growth of probiotic strains decreased $\mathrm{pH}$ value over time as shown in Figure 7 above, but significant differences ) $p<0.05$ ( were not observed among FCR, RR and FR hydrolysates of riceberry rice. L. reuteri KUB-AC5 fermentation of riceberry rice hydrolysates decreased $\mathrm{pH}$ ranging from 0.2 to 0.5 at $4 \mathrm{~h}, 2.0$ to 2.3 at $8 \mathrm{~h}$ and 2.2 to 2.4 at $16 \mathrm{~h}$ of incubation, while B. animalis TISTR 2194 decreased $\mathrm{pH}$ ranging from 0.2 to 0.3 at $6 \mathrm{~h}, 1.6$ to 1.8 at $12 \mathrm{~h}$ and 2.2 to 2.5 at 24 $\mathrm{h}$ of incubation. Also, B. bifidum TISTR 2129 caused $\mathrm{pH}$ reduction of 0.2 to 0.3 at $6 \mathrm{~h}, 1.7$ to 1.8 at $12 \mathrm{~h}$ and 2.1 to 2.3 at $24 \mathrm{~h}$ of incubation. Reductions in $\mathrm{pH}$ were attributed to liberation of organic acids, reflecting production of short chain fatty acids )SCFA( by the fermentation of riceberry rice hydrolysates. The effect on growth of bifidobacteria and lactobacilli rather than pathogens indicated the fermentable ability of riceberry rice hydrolysates by protobiotics. Studies conducted on humans fed diets rich in resistant starches revealed changes of major groups of bacteria including bifidobacteria and lactobacilli (Bertoft, 2004; Phillips et al., 1995; Tomlin and Read, 1990). Also, hydrolysates of Thai jasmine rice selectively enhanced probiotic bacterial growth in tandem with $\mathrm{pH}$ reduction )Ayimbila and Keawsompong, 2018(. Fermentation of starch by lactic acid bacteria releases organic acids such as SCFA's that reduce $\mathrm{pH}$ (Šušković, Kos, Goreta and Matošić, 2001)

Specific growth rate $) \mu, \mathrm{h}^{-1}($

\begin{tabular}{llllllll}
\multicolumn{6}{l}{ Table 3 Specific growth rate $(\mu)$ of test strains of probiotics and pathogens grown in medium with or without riceberry rice hydrolysates. } \\
\hline $\begin{array}{l}\text { Bacterial } \\
\text { strain }\end{array}$ & Basal medium & FCR-RCM & RR-RCM & FR-RCM & FCR-BM & RR-BM & FR-BM \\
\hline L. reuteri AC5 & $0.91 \pm 0.00^{\mathrm{b}}$ & $0.97 \pm 0.01^{\mathrm{a}}$ & $0.96 \pm 0.001^{\mathrm{a}}$ & $0.95 \pm 0.001^{\mathrm{a}}$ & $0.95 \pm 0.02^{\mathrm{a}}$ & $0.96 \pm 0.01^{\mathrm{a}}$ & $0.95 \pm 0.004^{\mathrm{a}}$ \\
B. bifidum TISTR 2129 & $0.94 \pm 0.02^{\mathrm{b}}$ & $1.04 \pm 0.02^{\mathrm{a}}$ & $1.03 \pm 0.01^{\mathrm{a}}$ & $1.02 \pm 0.02^{\mathrm{a}}$ & $1.03 \pm 0.01^{\mathrm{a}}$ & $1.01 \pm 0.004^{\mathrm{a}}$ & $1.02 \pm 0.03^{\mathrm{a}}$ \\
B. animalis 2194 & $0.86 \pm 0.03^{\mathrm{d}}$ & $0.95 \pm 0.01^{\mathrm{c}}$ & $0.94 \pm 0.02^{\mathrm{c}}$ & $0.93 \pm 0.02^{\mathrm{c}}$ & $0.94 \pm 0.01^{\mathrm{c}}$ & $0.94 \pm 0.03^{\mathrm{c}}$ & $0.94 \pm 0.01^{\mathrm{c}}$ \\
E. coli E010 & $0.92 \pm 0.01^{\mathrm{b}}$ & $0.96 \pm 0.01^{\mathrm{a}}$ & $0.95 \pm 0.02^{\mathrm{b}}$ & $0.96 \pm 0.01^{\mathrm{a}}$ & $0.96 \pm 0.02^{\mathrm{a}}$ & $0.97 \pm 0.01^{\mathrm{a}}$ & $0.96 \pm 0.02^{\mathrm{a}}$ \\
S. Enteritidis S003 & $0.93 \pm 0.003^{\mathrm{b}}$ & $0.94 \pm 0.01^{\mathrm{a}}$ & $0.95 \pm 0.02^{\mathrm{a}}$ & $0.95 \pm 0.02^{\mathrm{a}}$ & $0.93 \pm 0.03^{\mathrm{a}}$ & $0.94 \pm 0.02^{\mathrm{a}}$ & $0.94 \pm 0.03^{\mathrm{a}}$ \\
\hline
\end{tabular}

Freeze-dried hydrolysates of freshly cooked riceberry )FCR-RCM(, refrigerated riceberry )RR-RCM(, frozen riceberry )FR-RCM( by rice cooker method, and freshly cooked riceberry )FCR-BM(, refrigerated riceberry )RR-BM(, and frozen riceberry )FR-BM( by boiling method. Different letters as superscripts a, b, c and $\mathrm{d}$ show significant differences.

Table 3 shows specific growth rates $) \mu \mathrm{h}^{-1}$ ( of strains tested on riceberry rice hydrolysates compared to the control )without hydrolysate(. Differences in specific growth rates compared to the control among treatments for $L$. reuteri KUB-AC5 ranged from 0.03 to 0.05 , while $B$. animalis TISTR 2194 ranged from
0.05 to 0.07 . Likewise, specific growth rates of $B$. bifidum TISTR 2129 ranged from 0.08 to 0.10 . Also, E. coli $\mathrm{E} 010$ gave specific growth rates ranging from 0.01 to 0.03 , whereas those of $S$. serovar Enteritidis S003 ranged from 0.01 to 0.02 . Results indicated that probiotic strains gave higher specific growth rates than pathogens. Among the probiotics, B. animalis subsp. animalis TISTR 2194 produced the highest specific growth rates, followed by $L$. reuteri AC-5 and lastly, B. bifidum TISTR 2129. Riceberry rice hydrolysates enhanced rapid multiplication of probiotics and provided growth advantage for probiotic strains Changes in bacteria growth in the microbiota occur rapidly after dietary changes. 
Bacteria that can ferment resistant starch generate energy which provides them with growth advantages in the gut microbiota )Walker et al., 2011(. Thai jasmine rice hydrolysate consistently promoted probiotics growth in in vitro fermentation )Ayimbila and Keawsompong, 2018(.

\section{CONCLUSIONS}

Riceberry rice RS content was not significantly different between cooking methods and storage temperatures. However, SDS increased in riceberry rice cooked by boiling method due to a decrease in RDS after storage. SDS increased from $7.56 \%$ to $16.00 \%$ in RR-BM and by $15.81 \%$ in FR-BM. Also, riceberry rice hydrolysate after simulated hydrolysis in the human upper gut was not significantly different and $49.90 \%$ escaped hydrolysis. During in vitro fermentation, riceberry rice hydrolysate significantly enhanced growth of probiotic strains but significant $) p>0.05$ ( differences in growth changes over time were not observed among treatments. Probiotic strains gave specific growth rates ranging from $0.02-0.08$, higher than pathogens, and coupled with $\mathrm{pH}$ reduction. This demonstrated that starch fractions of riceberry rice were affected by processing conditions but not colonic fermentation of the hydrolysate. A deeper understanding of the prebiotic properties of riceberry rice hydrolysate is urgently required.

Acknowledgement: The authors are extremely grateful to the Faculty of AgroIndustry, Department of Biotechnology, Kasetsart University for providing facilities and funding under "scholarship for international graduate students."

\section{REFERENCES}

AYIMBILA, F., KEAWSOMPONG, S. 2018. In Vitro Starch Digestion and Colonic Fermentation of Thai Jasmine Rice. Starch-Stärke, 70(9-10), 1800049. https://doi/abs/10.1002/star.201800049

BERTOFT, E. 2004. Lintnerization of two Amylose-free starches of A-and BCrystalline types, respectively. Starch-Stärke, 56(5), 167-180. https://doi.org/10.1002/star.200300255

CERVANTES-PAHM, S. K., LIU, Y., STEIN, H. H. 2014. Comparative digestibility of energy and nutrients and fermentability of dietary fiber in eight cereal grains fed to pigs. Journal of the Science of Food and Agriculture, 94(5), 841-849. https://doi.org/10.1002/jsfa.6316

DUPONT, A. W., DUPONT, H. L. 2011. The intestinal microbiota and chronic disorders of the gut. Nature Reviews Gastroenterology and Hepatology, 8(9), 523-531. https://doi.org/10.1038/nrgastro.2011.133

ENGLYST, H. N., KINGMAN, S., CUMMINGS, J. 1992. Classification and measurement of nutritionally important starch fractions. European journal of clinical nutrition, 46, S33-50

FLINT, H. J., DUNCAN, S. H., SCOTT, K. P., LOUIS, P. 2007. Interactions and competition within the microbial community of the human colon: links between diet and health. Environmental microbiology, 9(5), 1101-1111. https://doi.org/10.1111/j.1462-2920.2007.01281

FREI, M., SIDDHURAJU, P., BECKER, K. 2003. Studies on the in vitro starch digestibility and the glycemic index of six different indigenous rice cultivars from the Philippines. Food Chemistry, 83(3), 395-402. https://doi.org/10.1016/s0308-8146(03)00101-8

FUENTES-ZARAGOZA, E., SÁNCHEZ-ZAPATA, E., SENDRA, E., SAYAS, E., NAVARRO, C., FERNÁNDEZ-LÓPEZ, J., PÉREZ-ALVAREZ, J. A. 2011 Resistant starch as prebiotic: A review. Starch-Stärke, 63(7), 406-415. https://doi.org/10.1002/star.201000099

GIBSON, G. R., PROBERT, H. M., VAN LOO, J., RASTALL, R. A., ROBERFROID, M. B. 2004. Dietary modulation of the human colonic microbiota: updating the concept of prebiotics. Nutrition research reviews, $17(2)$, 259-275. https://doi.org/10.1079/nrr200479

GIBSON, G. R., ROBERFROID, M. B. 1995. Dietary modulation of the human colonic microbiota: introducing the concept of prebiotics. The Journal of nutrition, 125(6), 1401. https://doi.org/10.1038/nrgastro.2017.75

HONGPATTARAKERE, T., CHERNTONG, N., WICHIENCHOT, S., KOLIDA, S., RASTALL, R. A. 2012. In vitro prebiotic evaluation of exopolysaccharides produced by marine isolated lactic acid bacteria. $\begin{array}{llll}\text { Carbohydrate } & \text { Polymers, } & 87(1), & 846-852\end{array}$ https://doi.org/10.1016/j.carbpol.2011.08.085

JULIANO, B., PEREZ, C., BLAKENEY, A., CASTILlO, T., KONGSEREE, N., LAIGNELET, B., . . . WEBB, B. 1981. International cooperative testing on the amylose content of milled rice. Starch-Stärke, 33(5), 157-162. https://doi.org/10.1002/star.19810330504

KURIKI, T., IMANAKA, T. 1999. The concept of the $\alpha$-amylase family: structural similarity and common catalytic mechanism. Journal of Bioscience and Bioengineering, 87(5), 557-565. https://doi.org/10.1016/s1389-1723(99)80114-5 LEE, H., LEE, S. H., KIM, J. C. 2017. Retrogradation of heat-gelatinized rice grain in sealed packaging: investigation of moisture relocation. Food Science and Technology (Campinas), 37(1), 97-102. ttps://doi.org/10.1590/1678-457x.07816 LEE, Y. K., SALMINEN, S. 2009. Handbook of probiotics and prebiotics: John Wiley \& Sons. https://doi.org/10.1002/9780470432624
MAROTTI, I., BREgOlA, V., ALOISIO, I., DI GIOIA, D., BOSI, S., DI SILVESTRO, R., . . . DINELLI, G. 2012. Prebiotic effect of soluble fibres from modern and old durum-type wheat varieties on Lactobacillus and Bifidobacterium strains. Journal of the Science of Food and Agriculture, 92(10), 2133-2140. https://doi.org/10.1002/jsfa.5597

OGAWA, Y., GLENN, G. M., ORTS, W. J., WOOD, D. F. 2003. Histological structures of cooked rice grain. Journal of agricultural and food chemistry, 51(24), 7019-7023. https://doi:10.1021/jf0347580

PHILLIPS, J., MUIR, J. G., BIRKETT, A., LU, Z. X., JONES, G. P., O'DEA, K., YOUNG, G. P. 1995. Effect of resistant starch on fecal bulk and fermentationdependent events in humans. The American journal of clinical nutrition, 62(1), 121-130. https://doi:10.1093/ajen/62.1.121

PHOTHICHITTO, K., NITISINPRASERT, S., KEAWSOMPONG, S. 2006 Isolation, screening and identification of mannanase producing microorganisms. $\begin{array}{llll}\text { Kasetsart } & J & \text { (Nat } & \text { Sci), }\end{array}$ https://doi.org/10.1016/j.pep.2017.07.005

RASHMI, S., UROOJ, A. 2003. Effect of processing on nutritionally important starch fractions in rice varieties. International journal of food sciences and nutrition, 54(1), 27-36. https://doi.org/10.1080/096374803/61976

REED, M. O., AI, Y., LEUTCHER, J. L., JANE, J. 2013. Effects of cooking methods and starch structures on starch hydrolysis rates of rice. Journal of food science, 78(7). https://doi.org/10.1111/1750-3841.12165

SINGH, J., KAUR, L., SINGH, H. 2013. Food microstructure and starch digestion. Advances in Food Nutritional Research, 70, 137-179. https://doi.org/10.1016/b978-0-12-416555-7.00004-7

SONIA, S., WITJAKSONO, F., RIDWAN, R. 2015. Effect of cooling of cooked white rice on resistant starch content and glycemic response. Asia Pacific journal of clinical nutrition, 24(4), 620-625. https://doi.org/10.1111/j.13652621.2010.02214.x

ŠUŠKOVIĆ, J., KOS, B., GORETA, J., MATOŠIĆ, S. 2001. Role of lactic acid bacteria and bifidobacteria in synbiotic effect. Food technology and biotechnology, 39(3), 227-235. https://doi.org/10.1023/a:1008909505651

TOMLIN, J., READ, N. 1990. The effect of resistant starch on colon function in humans. British Journal of Nutrition, 64(2), 589-595. https://doi.org/10.1079/bjn19900058

TUOHY, K., ROUZAUD, G., BRUCK, W., GIBSON, G. 2005. Modulation of the human gut microflora towards improved health using prebiotics-assessment of efficacy. Current pharmaceutical design, 11(1), 75-90. https://doi.org/10.2174/1381612053382331

VENTER, C. S. 2007. Prebiotics: an update. Journal of Family Ecology and Consumer Sciences= Tydskrif vir Gesinsekologie en Verbruikerswetenskappe, 35(1), 17-25. https://doi.org/10.4314/jfecs.v35i1.52924

VULEVIC, J., RASTALL, R. A., GIBSON, G. R. 2004. Developing a quantitative approach for determining the in vitro prebiotic potential of dietary oligosaccharides. FEMS microbiology letters, 236(1), 153-159. https://doi.org/10.1111/j.1574-6968.2004.tb09641.x

WALKER, A. W., INCE, J., DUNCAN, S. H., WEBSTER, L. M., HOLTROP, G., ZE, X., . . BERGERAT, A. 2011. Dominant and diet-responsive groups of bacteria within the human colonic microbiota. The ISME journal, 5(2), 220. https://doi.org/10.1038/ismej.2010.118

WANG, S., COPELAND, L. 2013. Molecular disassembly of starch granules during gelatinization and its effect on starch digestibility: a review. Food and function, 4(11), 1564-1580. https://doi.org/10.1039/c3fo60258c

YOOK, C., ROBYT, J. F. 2002. Reactions of alpha amylases with starch granules in aqueous suspension giving products in solution and in a minimum amount of water giving products inside the granule. Carbohydrate research, 337(12), 1113-1117. https://doi.org/10.1016/s0008-6215(02)00107-6 